\title{
Principle Analysis and Parameter Optimization for Underactuated End- Effector Manipulator for Apple Picking
}

\author{
Yu Ya-xin ${ }^{*}, 1,2$, Wu Fei ${ }^{1}$, Zhu Rong ${ }^{1}$ and Zhang Fei ${ }^{1}$ \\ ${ }^{I}$ Faculty of Mechanical Engineering \& Automation, Zhejiang Sci-Tech University, China \\ ${ }^{2}$ Zhejiang Province Key Laboratory of Transplanting Equipment and Technology, China
}

\begin{abstract}
In this paper, the mechanical structure of an underactuated end-effector manipulator for apple-picking is presented. The structure is consisted of three identical fingers which are driven by one motor. Each finger is formed by three joints which are connected with connecting bar and gears. With operation of grasp and twist executed by the driven fingers, apple-picking action completed. Mathematical model of the mechanical structure is proposed. Kinematics simulation \& optimization software which have a Human-Computer Interaction interface is developed with Visual Basic visualization platform. Parameters which affect enveloping space mostly are analyzed. With processing and analyzing data which get from the software, a set of optimum structure parameters are obtained. A sample machine of the Endeffector Manipulator which is used for testing purpose is designed according to the optimum structure parameters.
\end{abstract}

Keywords: End-effector, envelope, kinematics, parameter design, underactuated.

\section{INTRODUCTION}

End-effector Manipulator is one of the core components of picking robot which grasp fruits directly $[1,2]$. The grasped fruit will be damaged if the grasping force big enough [3]. Study and analysis of end-effector manipulator play an important role in automated fruit picking. The kind of manipulators mainly include suck type, barrel type, vibration type and full-driven fingers type. However, all those types have disadvantages such as poor adaptability and fruit damage in picking operation [4-12]. In recent years, underactuated end-effector manipulators working for fruit picking were proved to be a new way to solve these problems [13, 14].

Scholars from different countries have done a lot of researches about underactuated end-effector manipulator. Gosselin group, from Canada Laval University, has developed a three-fingered underactuated end-effector manipulator which has 10 DOF $[15,16]$ while driven by only two motors. Mao Yichu [17] has designed an integrated robot finger with highunderactuated and anthropopathic properties. Luo Minzhou $[18,19]$ has researched and developed a two-fingered underactuated manipulator which is driven by differential bevel gears. In the realm of fruits and vegetables picking, scholars such as Cui peng and Li Qinchuan has done a lot of researches. In order to improve manipulator's adaptability in complex environment, Cui peng [20] has developed a bio-robot manipulator driven by tendon. Li Qinchuan [21] has created a ZSTU manipulator which can grab and enclose fruits precisely. In this paper, an underactuated end-effector manipulator for apple-picking is presented.

*Address correspondence to this author at the Faculty of Mechanical Engineering and Automation, Zhejiang Sci-Tech University, Hangzhou, 310018, China; Tel: 010-13185001173; E-mail: yyxin@zstu.edu.cn

\section{THE STRUCTURE AND WORKING PRINCIPLE}

The schematic diagram of the end-effector is shown in Fig. (1). It comprises driving portion and execution portion. In driving portion, sliding block 4 is driven by screw 1 which driven by stepmotor. Execution portion consists of three identical fingers (only 2 fingers shown in Fig. 1) which

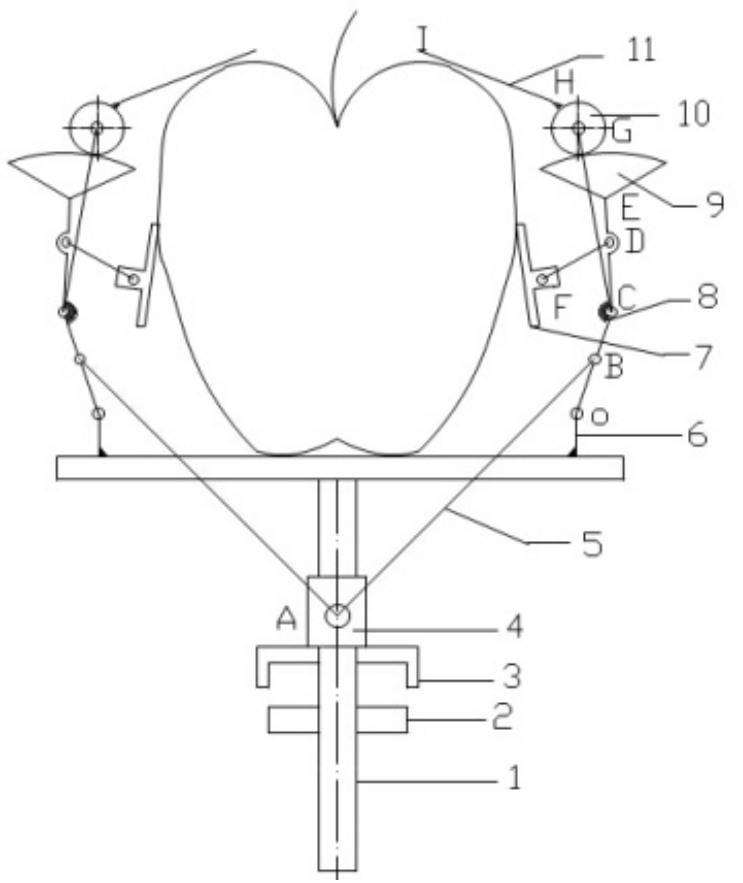

1 Screw lever, 2 Turning block, 3 Fitting block, 4 Sliding block, 5 Linkage 1, 6 The first joint 7 Plate, 8 Linkage2, 9 Sector gear, 10 Spur gear 11 The third joint

Fig. (1). Structure sketch for end actuator of an manipulator. 
placed evenly in peripheral direction, each finger is formed by three joints which are connected with connecting bar and gears. The first joint 6 is fixed with fixed disk. The second joint comprises a sector gear 9 (point $\mathrm{C}$ as rotation center), a spur gear 10 (point $\mathrm{G}$ as rotation center) and linkages. The third joint 11 fixed with spur gear 10. Torsion springs provide restoring force for every joint in every finger.

Working process of the manipulator as follow: The first step, linkage OC, linkage CG and joint HI driven by linkage $\mathrm{AB}$, move toward surface of fruit. The second step, plate 7 contacts with the fruit. With the help of interaction between immovable linkage DF and movable linkage $\mathrm{AB}$, sector gear 9 revolve around point C. Sector gear 9 drive spur gear 10 and joint $\mathrm{HI}$ revolving around point G. Grabbing action complete after joint $\mathrm{HI}$ contact with the fruit. The third step, turning block 2 embed into fitting block 3 , which leading the fruit turn with whole device. With a twist action, fruit picking action complete.

\section{KINEMATICS MODEL OF THE MECHANISM}

\subsection{Vector Equation}

The structure of the manipulator is consisted of three identical fingers. In order to simplify the kinematic model, only one of finger's kinetic features is analyzed. As we can see on Fig. (2), coordinate Oxy be built on point O. Closed vector polygons are drawn and vector equations are established.

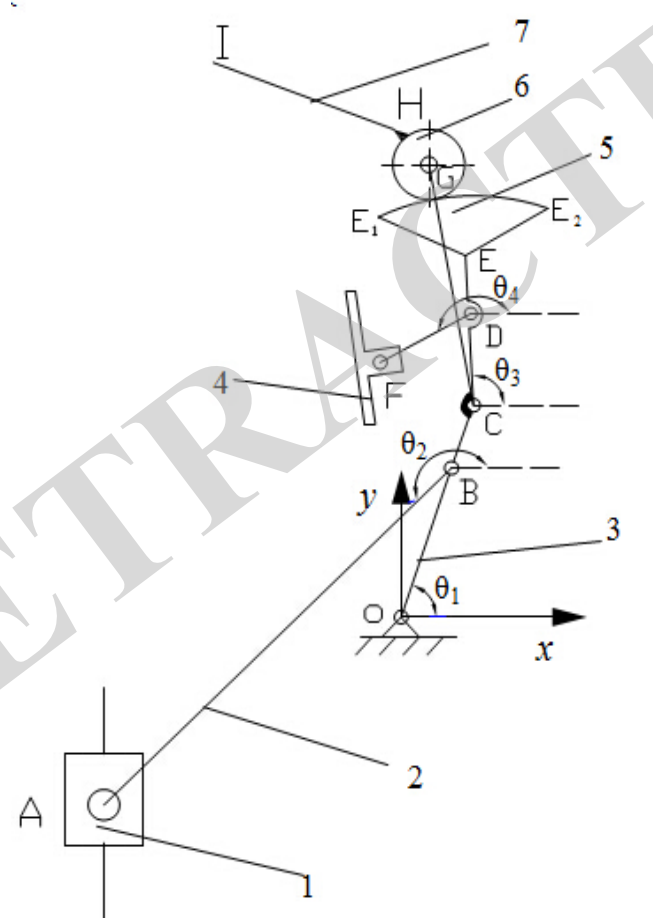

1 Sliding block, 2 Linkage AB, 3 Linkage OC, 4 Contact plate 5 Sector gear 6 Spur gear, 7 The third joint

Fig. (2). Sketch of the end actuator's finger.

$$
\left\{\begin{array}{l}
\overrightarrow{O B}+\overrightarrow{B A}=\overrightarrow{O A} \\
\overrightarrow{O F}+\overrightarrow{F D}+\overrightarrow{D C}=\overrightarrow{O C} \\
\overrightarrow{C G}+\overrightarrow{G H}=\overrightarrow{C H}
\end{array}\right.
$$

\subsection{Displacement Model}

According to vector equations, displacement equations are established.

$\left\{\begin{array}{l}O B \cos \theta_{1}+B A \cos \theta_{2}=x_{A} \\ O B \sin \theta_{1}+B A \sin \theta_{2}=y_{A}\end{array}\right.$

$\left\{\begin{array}{l}x_{C}=O C \cos \theta_{1} \\ y_{C}=O C \sin \theta_{1}\end{array}\right.$

Both $x_{A}$ and $y_{A}$ are known parameters. The first step, fingers move toward fruit, all components of the second and the third joints move as a rigid body.

$$
\begin{aligned}
& \left\{\begin{array}{l}
x_{D}=x_{C}+D C \cos \left(\pi+\theta_{1}-\alpha_{1}\right) \\
y_{D}=y_{C}+D C \sin \left(\pi+\theta_{1}-\alpha_{1}\right)
\end{array}\right. \\
& \left\{\begin{array}{l}
x_{F}=x_{c}-F D \cos \left(\theta_{1}-\alpha_{1}-\alpha_{2}\right)-D C \cos \left(\pi+\theta_{1}-\alpha_{1}\right) \\
y_{F}=y_{c}-F D \sin \left(\theta_{1}-\alpha_{1}-\alpha_{2}\right)-D C \sin \left(\pi+\theta_{1}-\alpha_{1}\right)
\end{array}\right. \\
& \left\{\begin{array}{l}
x_{H}=x_{G}+G H \cos \left(\theta_{1}-\alpha_{1}-\alpha_{3}\right) \\
y_{H}=y_{G}+G H \sin \left(\theta_{1}-\alpha_{1}-\alpha_{3}\right)
\end{array}\right. \\
& \left\{\begin{array}{l}
x_{I}=x_{H}+H I \cos \left(\theta_{I}-\alpha_{1}-\alpha_{3}\right) \\
y_{I}=y_{H}+H I \sin \left(\theta_{1}-\alpha_{1}-\alpha_{3}\right)
\end{array}\right.
\end{aligned}
$$

The second step, plate 4 touches the fruit, and sector gear 9 and spur gear 10 are engaged for driving. Final positions of first step are initial positions of second step.

$$
\begin{aligned}
& \left\{\begin{array}{l}
x_{D}=x_{C}+D C \cos \theta_{3} \\
y_{D}=y_{C}+D C \sin \theta_{3}
\end{array}\right. \\
& \left\{\begin{array}{l}
x_{F}=O C \cos \theta_{1}-F D \cos \theta_{4}-D C \cos \theta_{3} \\
y_{F}=O C \sin \theta_{1}-F D \sin \theta_{4}-D C \sin \theta_{3}
\end{array}\right. \\
& \left\{\begin{array}{l}
x_{H}=x_{G}+G H \cos \left(\theta_{1}-\alpha_{1}-\alpha_{3}+\Delta \theta_{3} \cdot r_{1} / r_{2}\right) \\
y_{H}=y_{G}+G H \sin \left(\theta_{1}-\alpha_{1}-\alpha_{3}+\Delta \theta_{3} \cdot r_{1} / r_{2}\right)
\end{array}\right. \\
& \left\{\begin{array}{l}
x_{I}=x_{H}+H I \cos \left(\theta_{1}-\alpha_{1}-\alpha_{3}+\Delta \theta_{3} \cdot r_{1} / r_{2}\right) \\
y_{I}=y_{H}+H I \sin \left(\theta_{1}-\alpha_{1}-\alpha_{3}+\Delta \theta_{3} \cdot r_{1} / r_{2}\right)
\end{array}\right.
\end{aligned}
$$

In those equations, $\alpha_{1}, \alpha_{2}, \alpha_{3}$ represent initial installation angle, $\angle C D F=\alpha_{2}, \angle C G I=\alpha_{3}, \angle B C G=\alpha_{4}$. $r_{1}$ and $r_{2}$ denote reference radius of sector gear and spur gear respectively.

\section{PARAMETER OPTIMIZATION BASED ON HUMAN- COMPUTER INTERACTION OPTIMIZATION METHODS}

Considering the size of mature fruits has a significant difference, the manipulator needs a wide clamping margin for fruit picking. Mechanism of the end-effector has very strong coupling between the parameters, belonging to multiple targets, multivariable optimization problem and the weighting factor could not be determined. According to the kinematics model, mechanism parameters are optimized and a set of optimal solutions are obtained. 


\subsection{Optimization Goals and Design Variables}

Red Fuji apples are chosen as picking samples. The physical properties of the apples are analyzed, data obtained as follows: diameter of the apples ranges from $60 \mathrm{~mm}$ to 95 $\mathrm{mm}$, height of the apples ranges from $50 \mathrm{~mm}$ to $85 \mathrm{~mm}$, weight of the apples ranges from $120.1 \mathrm{~g}$ to $220.4 \mathrm{~g}$

According to the kinematic characteristics, setting specific parameters are as follows:

(1) To ensure the picking stability of fingers, the first joint is fixed with fixed disk vertically; inclination range of the second joint is between $40^{\circ}$ and $60^{\circ}$.

(2) To ensure the manipulator have a good enveloping space in vertical direction, reference diameter $d_{1}$ of sector gear ranges from $60 \mathrm{~mm}$ to $65 \mathrm{~mm}$, reference diameter $d_{2}$ of spur gear ranges from $10 \mathrm{~mm}$ to $12 \mathrm{~mm}$.

(3) To ensure the manipulator's picking efficiency and safety, inclination $\theta_{3}$ of the third joint ranges from $90^{\circ}$ to $120^{\circ}$.

(4) To ensure that the contact plate has a good performance when contact with apple, length of the contact plate stretch out is between $10 \mathrm{~mm}$ and 30 $\mathrm{mm}$.

(5) Range of joints' length: CD: $10 \mathrm{~mm} \sim 26 \mathrm{~mm}$; DF: 13 $\mathrm{mm} \sim 25 \mathrm{~mm}$; BC: $10 \mathrm{~mm} \sim 20 \mathrm{~mm}$; HI: $22 \mathrm{~mm} \sim 32$ $\mathrm{mm}$.

\subsection{Human-Computer Interaction Optimization Software Based on VB}

According to kinematic models and parameter ranges listed above, in order that the manipulator has a good enveloping space, end-effector manipulator kinematics simulation software are developed on Visual Basic6.0 platform. Simulate grabbing and releasing action of the manipulator is shown on Fig. $(\mathbf{3} \mathbf{a}, \mathbf{b})$ respectively. User interface of the software is divided into motion display area, motion control area, parameter input area and kinematic curve display area, as shown in Fig. (4).

(a)

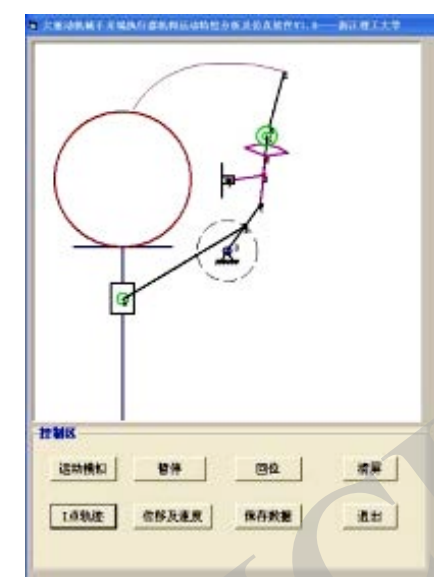

(b)

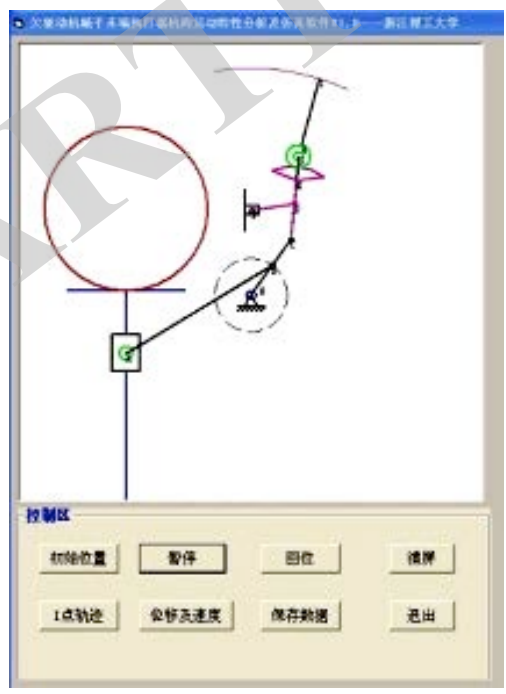

Fig. (3). Trajectory of mechanism. (a) Trajectory of grabbing action; (b) Trajectory of releasing action.

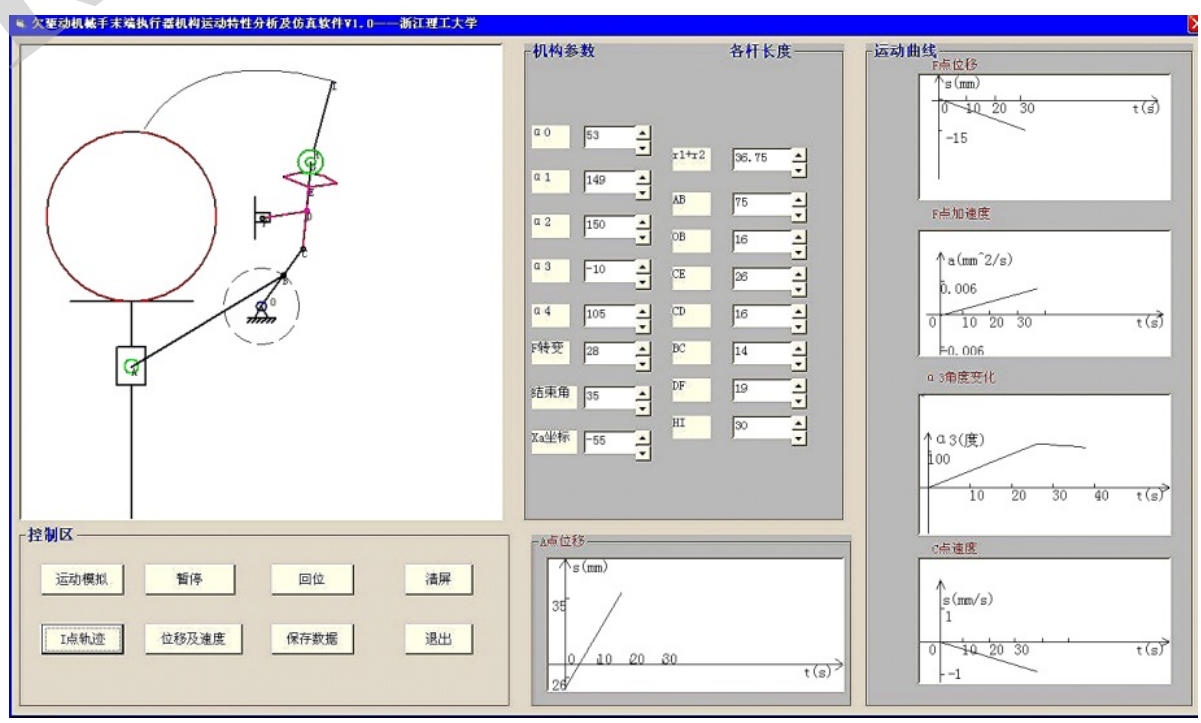

Fig. (4). Kinematics simulation and optimization software of end actuator. 


\subsection{Effects of Parameters on the Optimal Target}

According to mathematical models established and the optimization software, parameters which affect enveloping space most are analyzed. Size of enveloping space depends on displacements of fingers' end and contact plate. The parameters have significant effects on the displacements of $\mathrm{x}$-direction compare with the displacements of y-direction. Therefore, displacements referred in this paper are displacements of $\mathrm{x}$-direction. Initial value of parameters are given as follow: $\mathrm{BC}=14 \mathrm{~mm}, \mathrm{CD}=16 \mathrm{~mm}, \mathrm{HI}=30 \mathrm{~mm}$, $\mathrm{DF}=20 \mathrm{~mm}, \theta_{1}=53^{\circ}, \theta_{3}=110^{\circ}$. Only one of the parameters will be changed during optimization in one time. The displacements and the enveloping space can be analyzed easily with the help of the software.

The relationships between displacement of point I and length of joints are shown in Fig. (5). With the increase in length of joint $\mathrm{BC}$, displacement of point $\mathrm{I}$ changes apparently. In addition, inflection of the displacement curve occurs frequently (illustrated in Fig 5a). With the increase in length of joint HI, displacement of point I changes faintly, as shown in the Fig. (5b). Compare with joint HI, joint BC has more effects on point I's displacement and hence length of joint $\mathrm{BC}$ is priority parameter.

(a) Effects of joint BC

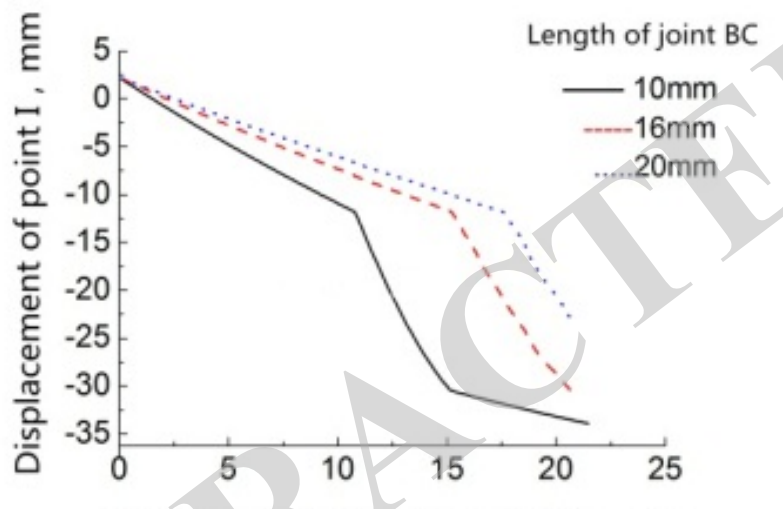

Displacement of sliding block $1, \mathrm{~mm}$

(b) Effects of joint $\mathrm{HI}$

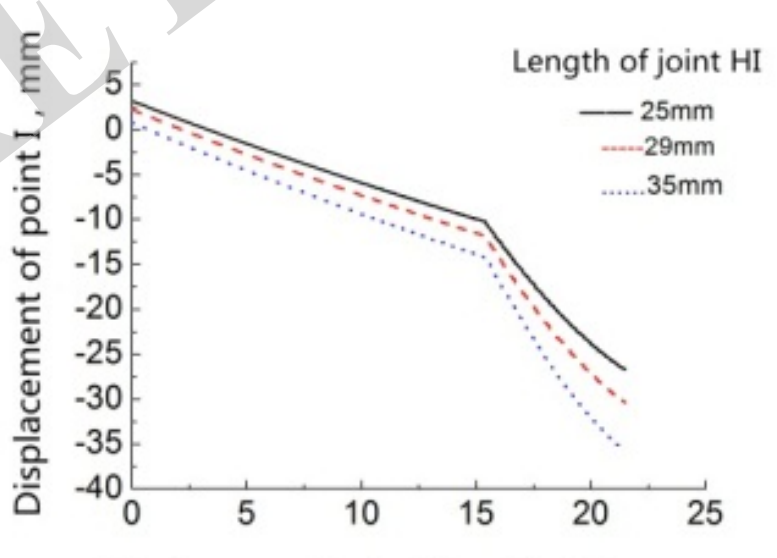

Displacement of sliding block $1, \mathrm{~mm}$
The relationships between displacement of point I and initial angles are shown in Fig. (6). Compare with $\theta_{3}, \theta_{1}$ has more effects on point I's displacement and hence $\theta_{1}$ is priority parameter.

(a) Effects of $\theta_{1}$

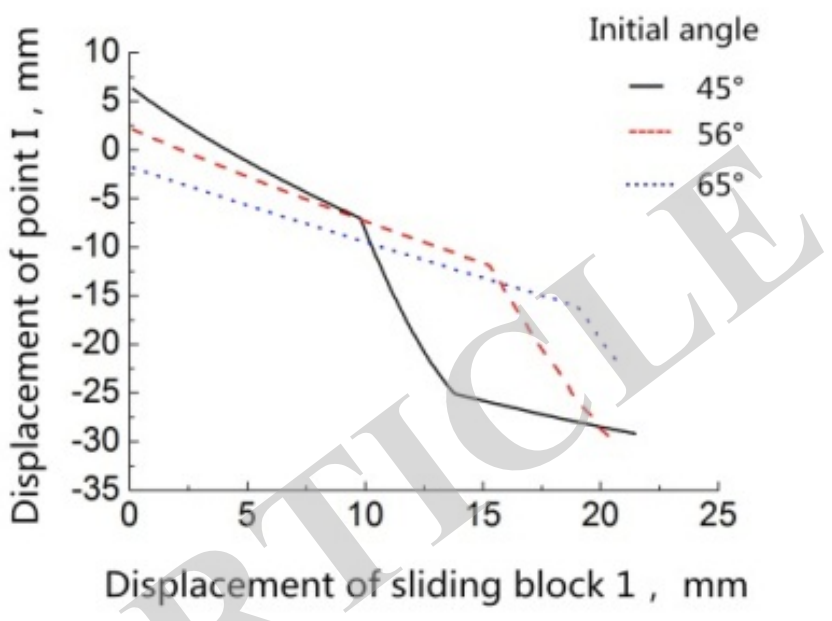

(b) Effects of $\theta_{3}$

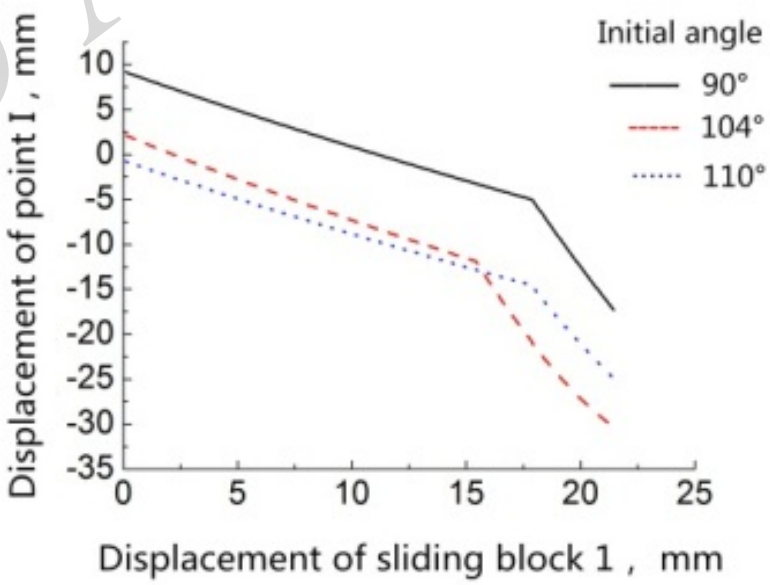

Fig. (6). Effects of angles on displacement.

Through above analysis, effects of various parameters on endpoint's displacement are different. It also means that effects of various parameters on enveloping space are different. In order to observe the effects in a visual way, alterations of the displacements are converted into diameter of ball. From this, enveloping space can be represented as volume of ball. Stroke of sliding block 1 is a setting value. Variation curves of balls' diameter are shown in Fig. (7).

Diameter of enveloping ball ranges from $89.97 \mathrm{~mm}$ to $68.12 \mathrm{~mm}$ when set length $\mathrm{CD}$ in range of $10 \mathrm{~mm}$ to $26 \mathrm{~mm}$.

Diameter of enveloping ball ranges from $96.28 \mathrm{~mm}$ to $53.25 \mathrm{~mm}$ when set length DF in range of $13 \mathrm{~mm}$ to $25 \mathrm{~mm}$.

Diameter of enveloping ball ranges from $90.80 \mathrm{~mm}$ to $75.12 \mathrm{~mm}$ when set length $\mathrm{BC}$ in range of $10 \mathrm{~mm}$ to $20 \mathrm{~mm}$.

Fig. (5). Effects of length on displacement. 
Diameter of enveloping ball ranges from $89.15 \mathrm{~mm}$ to $77.16 \mathrm{~mm}$ when set length $\mathrm{HI}$ in range of $22 \mathrm{~mm}$ to $32 \mathrm{~mm}$.

In the given conditions, initial angle $\theta_{1}$ is set in sequence as follow: $47^{\circ}, 49^{\circ}, 51^{\circ}, 53^{\circ}, 55^{\circ}$ and $57^{\circ}$. In consequence, Diameter of enveloping ball as follows: $97.63 \mathrm{~mm}, 94.59$ $\mathrm{mm}, 90.73 \mathrm{~mm}, 87.59 \mathrm{~mm}, 77.97 \mathrm{~mm}$ and $62.00 \mathrm{~mm}$.

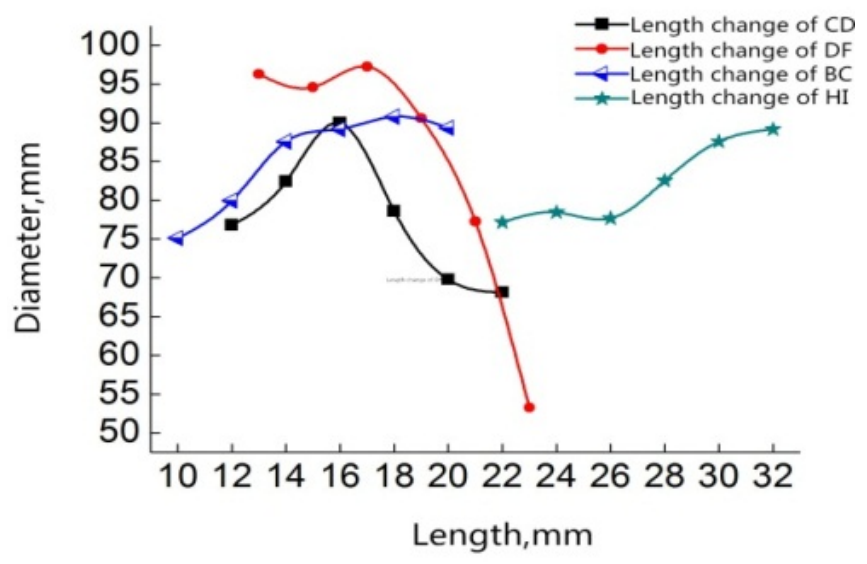

Fig. (7). Effects of length of fingers on enveloping space.

\subsection{Result of Optimization}

Through a comprehensive analysis of effects of various parameters, a set of optimized parameters obtained as follow: Stroke of sliding block $22 \mathrm{~mm}$, length of joint BC $16 \mathrm{~mm}$, length of joint HI $29 \mathrm{~mm}$, length of CD $16 \mathrm{~mm}$, length of DF $19 \mathrm{~mm}$, initial angle $\theta_{1} 56^{\circ}$, initial angle $\theta_{2} 109^{\circ}$, initial angle $\theta_{3} 104^{\circ}$. Diameter of enveloping space ranges from $55 \mathrm{~mm}$ to $97 \mathrm{~mm}$. Input all optimized parameters into the simulation software. The displacement curve of point I and point $\mathrm{F}$ obtained as shown in Fig. (8).

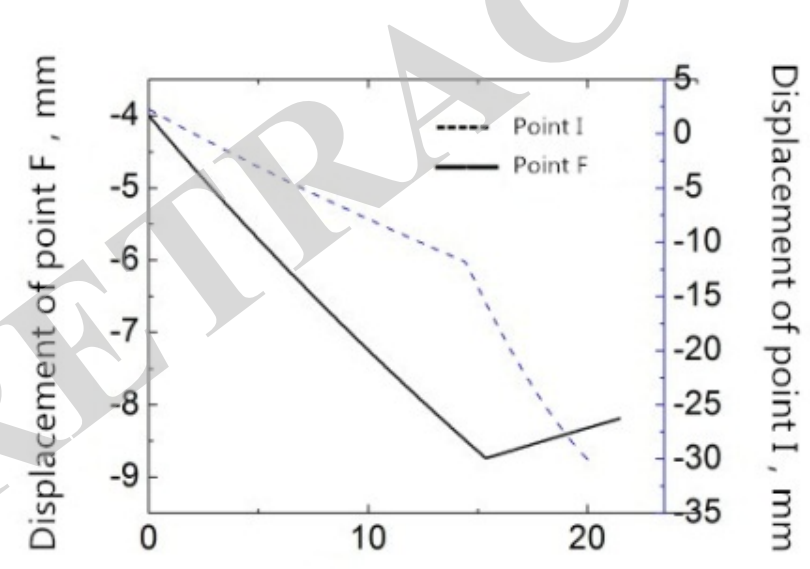

Displacement of sliding block $1, \mathrm{~mm}$

Fig. (8). Displacement of contact points by simulation.

\section{PROTOTYPE OF END-EFFECTOR}

Based on theoretic analysis and obtained parameters, prototype of the end-effector for testing purpose is produced. Grabbing and releasing state of end-effector are shown in Fig. (9). (a) Grabbing state

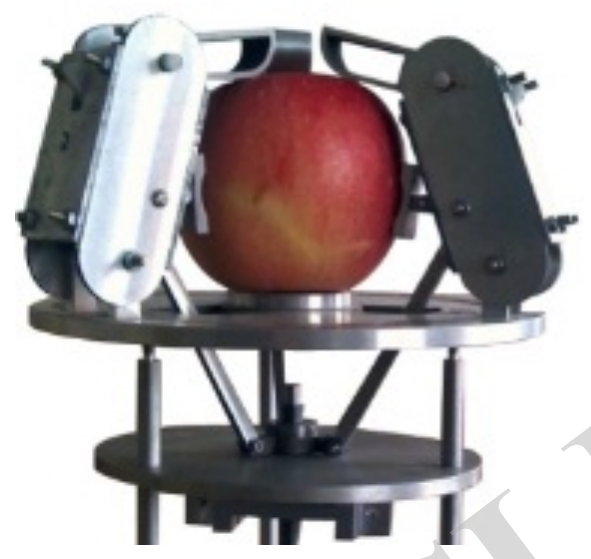

(b) Releasing state

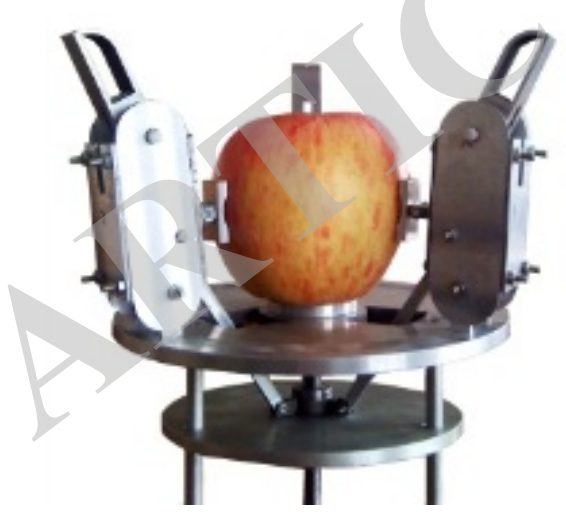

Fig. (9). Prototype of end-effector.

\section{CONCLUSION}

The mechanical structure of underactuated end-effector manipulator for apple-picking is presented. The end-effector which can execute apple-picking operation by grasping and twisting is comprised of connecting bar and gears.

Mathematical model of the mechanical structure is proposed. Kinematics simulation \& optimization software which have a Human-Computer Interaction interface is developed. Mechanism Parameters of end-effector are adjusted and optimized with the help of kinematics simulation \& optimization software.

With analyzing and processing data which get from the software, a set of optimum structure parameters are obtained as follow: Stroke of sliding block $22 \mathrm{~mm}$, length of joint $\mathrm{BC}$ $16 \mathrm{~mm}$, length of joint HI $29 \mathrm{~mm}$, length of CD $16 \mathrm{~mm}$, length of DF $19 \mathrm{~mm}$, initial angle $\theta_{1} 56^{\circ}$, initial angle $\theta_{2} 109^{\circ}$, initial angle $\theta_{3} 104^{\circ}$.

A sample machine of the end-effector is designed according to the optimum structure parameters. Follow-up work is mainly on the experiment about enveloping effectiveness and contact force of the sample machine.

\section{CONFLICT OF INTEREST}

The authors confirm that this article content has no conflict of interest. 


\section{ACKNOWLEDGEMENTS}

This work was supported by Zhejiang Sci-Tech University 521 talent cultivation program and Zhejiang provincial Natural Science Foundation of China (No. LY12E05028).

\section{REFERENCES}

[1] Zhao Y, Wu C, Hu X, Yu G. Research progress and problems of agricultural robot. Trans Chin Soc Agric Eng 2003; 19(1): 20-4.

[2] Zhang L, Hu H, Ji S, Xu F. Review of non-destructive quality evaluation technology for fruit and vegetable products. Trans Chin Soc Agric Eng 2005; 21(4): 176-80.

[3] Song J, Zhang T, Xu L, Tang X. Research actuality and prospect of picking robot for fruits and vegetables. Trans Chin Soc Agric Mach 2006; 37(5): 158-62.

[4] Zhen Y, Zhang H, Chen W, Zhu ZC. A Full-drive Dexterous Manipulator. China. ZL201020666505, 2010.

[5] Ma L, Yang W, Wang C, et al. Structure design and experiment of the end-effector for apple-harvesting robot. J Agric Mech Res 2009; (12): 65-7.

[6] Hua D, Hua Z. Linkage mechanism design and application innovation. Beijing, China: Mechanical Industry Press 2007.

[7] Monta M, Kondo N, Ting KC. End-effectors for tomato harvesting robot. Artif Intell Rev 1998; 12(1-3): 11-25.

[8] Liu J, Li P, Li Z. Hardware design of the end-effector for tomatoharvesting robot. Trans Chin Soc Agric Mach 2008; 39(3): 109-12.

[9] Xu L, Zhang T. Present situation of fruit and vegetable harvesting robot and its key problems and measures in application. Trans Chin Soc Agric Eng 2004; 20(5): 38-42.
[10] Fon D, van Weel PA, Buwalda F. Development of a new tomato production system Research Station for Flo-riculture. Trans Chin Soc Agric Mach1995; 3(1): 15-29.

[11] Tang Z, Meng X, Shen C, et al. Design and experimental investigation of mechanical vibration tree fruits and nutsharvester. J Agric Mech Res 2010; 8: 56-9.

[12] Liu C, Zhang T, Yang L. Design of End-effecter of eggplant harvesting robot. J Agric Mech Res 2008; 12: 62-4.

[13] Li X, Ren H. Motion analysis and application research on the nderactuated mechanism. Mech Res Appl 2010; 23(12): 29-31.

[14] Ying Y, Li Q, Wu C, et al. Underactuated Finger Device Has Properties of Preventing degradation 2007, China. ZL200710071186.

[15] Birglen L, Gosselin CM. On the force capability of underactuated fingers. Int Conf Robotics Automat, Taipei, Taiwan 2003; pp. 1139-1145.

[16] Birglen L, Gosselin CM. Geometric design of three-phalanx underactuated finger. ASME J Mech Des 2006; 128(2): 356-64.

[17] Mao Y, Zhu X, Li S, Yang F. Design of a naw underactuated prosthetic hand. Mach Des Res 2008. 24(3): 33-8.

[18] Luo M, Mei T, Wang X. Design of a shape self-adaptive underactuated robot finger with three phalanges. J Comput Aided Des Comput Graph 2005; 17(2): 353-8.

[19] Luo M, Mei T, Lu C, Yu Y. Analysis and simulation of enveloping graspstability of the multi phalange underactuated robot hand. Optics Precis Eng 2004; 12(5): 510-7.

[20] Cui P, Chen Z, Zhang X. Statics analysis of apple-picking robot humanoid manipulator. Trans Chin Soc Agric Mach 2011; 42(2): $149-53$.

[21] Li Q, Hu T, Wu C, Hu X, Ying Y. Review of end-effectors in fruit and vegetable harvesting robot. Trans Chin Soc Agric Mach 2008; 39(3): 175-9.

Received: April 14, 2015

Revised: May 21, 2015

Accepted: May 25, 2015

(C) Ya-xin et al.; Licensee Bentham Open.

This is an open access article licensed under the terms of the Creative Commons Attribution Non-Commercial License (http://creativecommons.org/licenses/ by-nc/3.0/) which permits unrestricted, non-commercial use, distribution and reproduction in any medium, provided the work is properly cited. 